\title{
Evaluation of dynamic pass-through of carbon prices into electricity prices - a cointegrated VECM analysis
}

\author{
Carlos J. Pereira Freitas \\ Institute of Engineering, Polytechnic of Porto (ISEP), \\ Rua Dr. António Bernardino de Almeida, \\ 431, 4200-072 Porto, Portugal \\ and \\ Faculty of Economics, \\ University of Coimbra, \\ Av. Dias da Silva, \\ 165, 3004-512 Coimbra, Portugal \\ E-mail: cpf@isep.ipp.pt
}

\section{Patrícia Pereira da Silva*}

Faculty of Economics, University of Coimbra, Av. Dias da Silva, 165, 3004-512 Coimbra, Portugal

and

INESC Coimbra,

Rua Antero de Quental,

199, 3030-030 Coimbra, Portugal

E-mail: patsilva@fe.uc.pt

*Corresponding author

\begin{abstract}
This paper addresses the impact of the $\mathrm{CO}_{2}$ opportunity cost on the wholesale electricity price in the context of the Iberian electricity market (MIBEL), namely on the Portuguese system, for the period corresponding to the Phase II of the European Union Emission Trading Scheme (EU ETS). In the econometric analysis a vector error correction model (VECM) is specified to estimate both long-run equilibrium relations and short-run interactions between the electricity price and the fuel (natural gas and coal) and carbon prices. The model is estimated using daily spot market prices and the four commodities prices are jointly modelled as endogenous variables. Moreover, a set of exogenous variables is incorporated in order to account for the electricity demand conditions (temperature) and the electricity generation mix (quantity of electricity traded according the technology used). The outcomes for the Portuguese electricity system suggest that the dynamic pass-through of carbon prices into electricity prices is strongly significant and a long-run elasticity was estimated (equilibrium relation) that is aligned with studies that have been conducted for other markets.
\end{abstract}

Keywords: European Union Emission Trading Scheme; EU ETS; Iberian electricity market; cointegration; vector error correction model; VECM; European climate policy; Kyoto Protocol; carbon cost pass-through. 
Reference to this paper should be made as follows: Freitas, C.J.P. and da Silva, P.P. (xxxx) 'Evaluation of dynamic pass-through of carbon prices into electricity prices - a cointegrated VECM analysis', Int. J. Public Policy, Vol. X, No. Y, pp.000-000.

Biographical notes: Carlos J. Pereira Freitas is a Professor of Management at the Institute of Engineering, Polytechnic of Porto (ISEP), Portugal. His research interests, conducted at University of Coimbra, are in the environmental economics and policy, climate change economics and policy and energy markets.

Patrícia Pereira da Silva holds a PhD in Finance from the University of Coimbra (UC). Her research interests, conducted at INESCC, are in the areas of energy economics, energy finance and markets. She is a faculty member at the Faculty of Economics and at the Energy for Sustainability Initiative from UC, and also at the MIT-P program within the field of sustainable energy systems.

This paper is a revised and expanded version of a paper entitled 'Evaluation of dynamic pass-through of carbon prices into electricity prices - a cointegrated VECM analysis' presented at the 14th INFER (International Network for Economic Research) Annual Conference, Coimbra, 2012.

\section{Introduction}

The European Union (EU) has implemented a cap-and-trade system - emission trading scheme (EU ETS) on January 2005 as a tool to reach the emissions targets set forth by the Kyoto Protocol, which aimed reducing carbon emission by $8 \%$ by 2012 . In this regard, it is designed to operate in two phases, the first from 2005 to 2007, while the second spans the period from 2008 to 2012. Each of these phases corresponds to a national allocation plan (NAP) which specifies the total number of emissions allowances allocated (grandfathered ${ }^{1}$ ) to the individual installations covered by the scheme. Transactions of such allocated allowances are then made possible through an EU emissions allowances (EUA) market that provides a price for the $\mathrm{CO}_{2}$. The scheme covers several industry sectors of which electricity sector is the largest one. Therefore, the performance of EU ETS depends on environmental effectiveness (inducing electricity industry to cut $\mathrm{CO}_{2}$ emissions) and economic efficiency (ensure that the cuts would be made by those firms that could achieve the most efficient abatement costs) (European Commission, 2003). Furthermore, the EU ETS might also have a considerable distributive and welfare implications, impacting on consumer's surplus and firm's profits and competitiveness. Either the performance of the EU ETS or its distributive and welfare implications depends on what extent the $\mathrm{CO}_{2}$ emission allowances prices are passed through into electricity prices. This study focuses on this latter issue, analysing the impact of EUA prices on electricity pricing in the short and long run.

Economic theory explains why, under a cap-and-trade system, the price of emissions ought to be treated as a marginal cost. As a producer holds allowances, the electricity production, and $\mathrm{CO}_{2}$ emitting, competes with the possibility to sell those allowances in the market. This so-called $\mathrm{CO}_{2}$ opportunity cost equals the $\mathrm{CO}_{2}$ market price. While electricity producers may fully recognise the opportunity costs of $\mathrm{CO}_{2}$ allowances in their marginal production costs, these costs might not be totally passed through to electricity 
prices. Sijm et al. (2005) and Gullì (2008) give a set of reasons for the pass-through rate (PTR) of $\mathrm{CO}_{2}$ costs into electricity prices to be different from $100 \%$, including demand responses (price elasticity), level of power demand (peakload vs. off-peakload) market structure (degree of market concentration), technology mix (fuel used in production), or available generation capacity.

In this paper we empirically study the dynamic interaction between carbon prices, electricity prices and fuel prices (natural gas and coal) for the Iberian Electricity Market (MIBEL), in particular the Portuguese division for the Phase II of EU ETS (January 2008 to August 2011).

Estimating this interaction presents several challenges which we tried to address. First it is becoming well-known that dynamic interactions between power, carbon and fuel prices, which include feedback in a non-ceteris paribus environment, may play a fundamental role in the price formation process of electricity wholesale markets. To address this issue, a multivariate analysis has been developed with a vector autoregressive (VAR) model, treating all variables (electricity price, fuel prices and EUA prices) as jointly endogenous. Second, as we are working on economic data there are strong beliefs that prices series are non-stationary, demanding a careful analysis of incurring in the risk of spurious regression. Because all variables in the analysis are cointegrated, we focus on this issue by modelling the problem in an error correction form.

According to our knowledge, this is the first work trying to empirically estimate the PTR of $\mathrm{CO}_{2}$ emissions costs to electricity prices in the Portuguese electricity market. Further, we believe the methodological approach herein presented additionally introduces some innovation in the state of the art (empirical research in measuring pass-through of $\mathrm{CO}_{2}$ costs into commodities or products prices) in respect to the treatment given to the exogenous variables (temperature and quantity of electricity traded according the technology used in electricity production).

The remainder of the paper is organised as follows. Section 2 presents a brief literature review. Section 3 describes the functioning of MIBEL. Section 4 describes the methodological approach. Section 5 presents the data used for the empirical estimation. Section 6 presents the empirical findings. Section 7 concludes.

\section{Literature review}

The interaction between carbon prices and electricity prices has been examined in several other studies. Prior to the emergence of actual carbon trading in practice, extensive theoretical (equilibrium analysis) and simulations analysis had speculated upon its effectiveness. Regarding the EU ETS impact in the European power sector in particular, Wals and Rijkers (2003) and Sijm et al. (2005) simulated with the COMPETES ${ }^{2}$ model the setting for Germany, Netherlands, Belgium and France markets. Using the same model, Chen et al. (2008) comment upon the northwest Europe region and Lise et al. (2010) simulated the effect on several European countries, including the Iberian countries (Portugal and Spain) which is particularly relevant for our study. Hauch (2003) comments upon the Nordic circumstances, Linares et al. (2006) on Spanish case, Neuhoff et al. (2006) on the UK case, Kara et al. (2008) on the NordPool market (Denmark, Finland, Sweden and Norwegian) and Frondel et al. (2008) in German market. Burtraw and Palmer (2008) discuss the case of the USA. Empirical evidence provided from 
phase I of EU ETS, ended at the end of 2007, has been discussed extensively on two directions:

1 econometric studies on price formation of EUA: (Mansanet-Bataller et al., 2007; Alberola et al., 2008, 2009; Hintermann, 2010; Rickels et al., 2010) which also use data from the first years of the second phase, and (Chevallier, 2010), in that case for the Australian market

2 econometric studies on the pass through rate of emission allowance prices into product prices, notably electricity and energy intensive materials.

Concerning the electricity sector several studies have been examining the influence of carbon pricing on electricity prices: (Levy, 2005; Sijm et al., 2006; Reinaud, 2007; Zachmann and von Hirschhausen, 2007; Sijm et al., 2008; Keppler and MansanetBataller, 2010) which already use data from the first year of phase II of EU TS, and (Daskalakis and Markellos, 2009), which consider the particular case of futures.

Most of published analyses conducted in order to estimate the PRT of $\mathrm{CO}_{2}$ cost into electricity prices have not yet reflected the mutual interactions between electricity price, fuel prices (natural gas, coal, fuel, oil) and carbon prices. In general, the bulk of those studies have solely relied on univariate analysis, which explain the price of one of these commodities (the endogenous variable) as a function of the prices of the others (the exogenous variables), without considering possible reciprocal causalities (endogeneities). One of the first studies taking into account those interdependencies was the analysis by Fezzi (2006), extended later in Bunn and Fezzi (2007) and Fezzi and Bunn (2009), where the authors, using multivariate analysis, modelled the prices of all variables as a joint system. Developing a vector error correction model (VECM), with the electricity, gas and carbon prices as endogenous variables and temperature as an exogenous regressor, the authors estimated the dynamic pass-through of $\mathrm{CO}_{2}$ price into electricity price for Germany and UK. Other studies have been following that econometric approach, a category where this article also belongs. Honkatukia et al. (2006) developed a similar model for the NordPool market considering the electricity, gas, coal and carbon prices as endogenous variables. Fell (2010), also for the NordPool and with the same prices variables, added the temperature and the reservoir water level ${ }^{3}$ as exogenous regressor to the VECM. Chemarin et al. (2008) estimated a VECM for the France power market considering the electricity, gas, oil and carbon as prices as endogenous and a two different weather variables: the temperature, affecting the demand side of electricity market, and rainfall influencing the electricity production of a country concerning its energy mix. Thoenes (2011), following a similar econometric approach, analyses the relationship between electricity, fuels and carbon prices for the German market.

Other works has been conducted in order to examine the long-run relation and short-run dynamics between electricity prices and fossil fuel prices. For instance, Mohammadi (2009) analyses the relation between the electricity prices and coal, natural gas and crude oil for the USA market, while Mjelde and Bessler (2009), for the same market added the uranium price to the analysis. Authors such as Ferkingstad et al. (2011) studied the Northern European electricity market case and Moutinho et al. (2011) the Spanish case. 


\section{MIBEL background}

The lack of storability in electricity sector means that production levels need to constantly match demand requirements. In fully competitive electricity markets the aggregated supply curve reflects the stack of increasing marginal costs offered by different power plants in order to produce electricity. Since electricity demand typically varies through the day and according the seasons, every power system needs low marginal cost (high capital cost) generation units operating baseload and flexible plant, typically with lower capital costs but higher marginal costs, producing intermittently at the peaks periods when prices case rise significantly allowing recover both fixed and variable costs (Bunn, 2004). A merit order or ranking of the supply technologies based on their marginal production costs, from the cheapest do the most expensive, can therefore be constructed. In the Portuguese electric system, since there is no nuclear power, baseload typically includes generation capacity which cannot be modulated, namely renewables $^{4}$ - wind power and run-of-river hydro plants. Reservoir hydroelectric power and pumped storage could be used in both baseload and peak load periods (especially in very rainfall winters). At the end of merit order subsist plants with low capital cost and high marginal costs - thermal fuel oil/gasoil plants, thermal coal plants and combined cycle gas turbine (CCGT). The question on the marginal unit at the peakload periods relies between thermal coal and CCGT because the full oil/gasoil plants were being phased out during the period of this study, as one can perceive in Table 1. Due to emissions trading, the marginal production costs of carbon inefficient technologies, in the Portuguese case coal-fired plants, increase substantially and that, subsequently, the relative position between coal and CCGT in the merit order may change due to carbon costs (Sijm et al., 2008). So, if thermal coal was the highest marginal cost technology than is expected that coal-fire power plants operate most at the peaks and CCGT at mid-merit hours.

Table 1 shows that the weight of each technology in electricity production (CCGT, thermal coal and hydroelectric), excluding renewables, is approximately 1/3. Hydroelectric power plants present the most variable production which naturally depends on the weather conditions, but also in thermal coal there is some variability which typically offsets the hydroelectric lower production years.

The MIBEL, the joint Portuguese-Spanish electricity market that came into effect in July 1, 2007, allows participants to trade power on either side of the Portugal/Spain border. The daily spot market (the purpose of this study) is managed by operator responsible for the electricity spot market (OMEL), located at Spain, while the derivatives market (futures and options) is managed by operator responsible for the electricity derivatives market (OMIP), located at Portugal. Wholesale electricity spot price formation in OMEL uses 'market splitting' procedure to solve cross-border congestion management (one single Iberian price area if there is no congestion in the interconnection between Spain and Portugal and with distinct price areas if there is congestion in the interconnection between both countries). Interconnection capacity makes it possible to trade electricity between countries (Pacheco, 2010). 
Table 1 Electricity production and generation capacity by technology

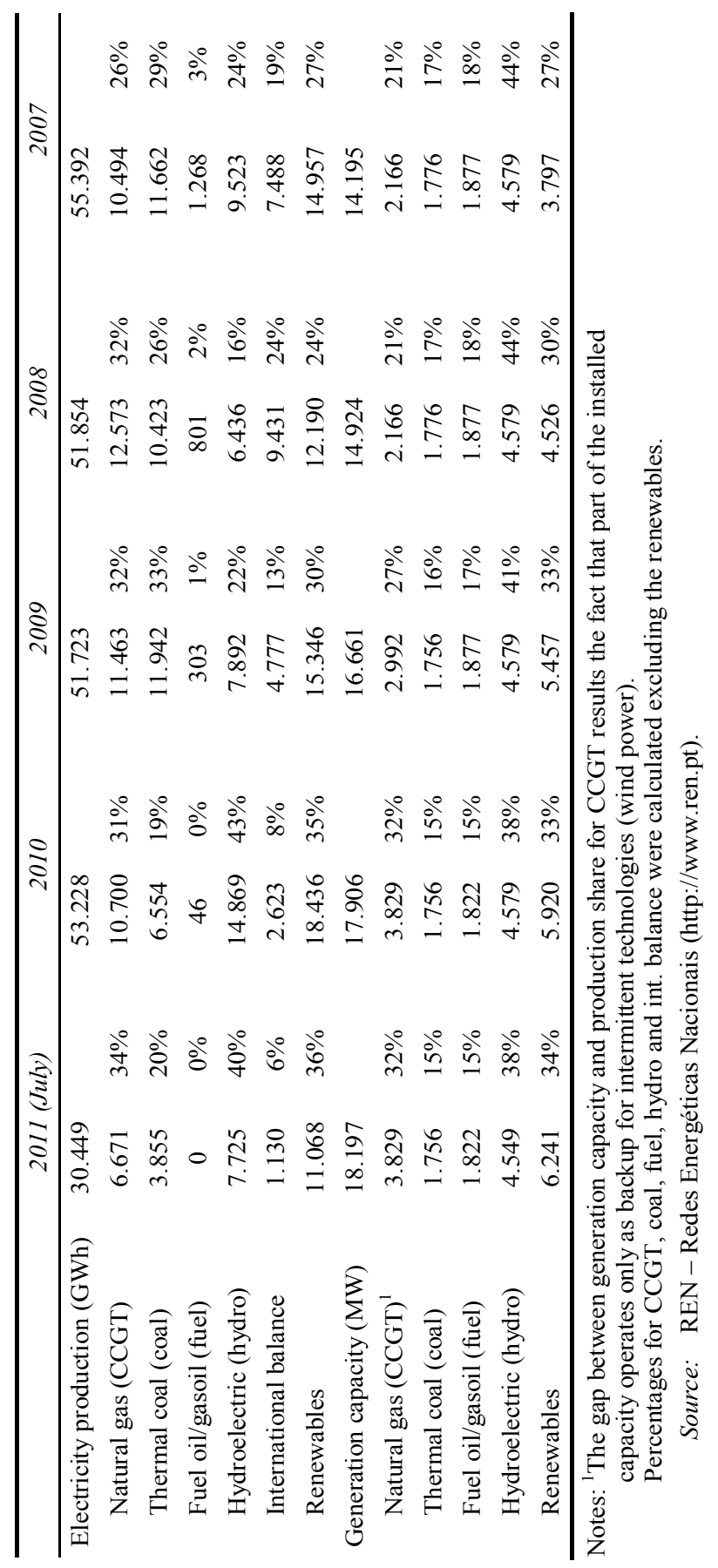


The influence of carbon on the price of electricity may not be constant across time. Even given full pass-through of $\mathrm{CO}_{2}$ costs, the $\mathrm{CO}_{2}$ emissions associated with electricity generation will be a function of generation fuel used. This in turn makes the increase in marginal cost of electricity generation due to $\mathrm{CO}_{2}$ market dependent upon the technology used in generation. In order to address this problem we have included in the econometric model a set of variables which we hope that works as a proxy of the marginal producer (the weight of each technology on the total energy traded in the market during a day).

Climate variables, such as temperature, rainfall or brightness may also influence the relationship between electricity and carbon prices. Temperature, which influences the behaviour of the population, may affect the demand side of the electricity market (Engle et al., 1986), and other weather conditions like rainfall and wind impact the supply side (production) of electric system with regard of its energy mix conditioning both the costs with fuels and the level of $\mathrm{CO}_{2}$ emissions. In this study we chose to incorporate in the model only the effects of climate variables on the demand side to the extent that we hope the supply side effects would be captured by the energy mix variables mentioned above.

\section{Empirical methodology}

Empirical research in measuring pass-through of $\mathrm{CO}_{2}$ costs into commodities or products prices, including the electricity price, typically applies one of two modelling techniques: univariate approach, with a single equation regression, or multivariate approach. Recent studies have been confirmed that dynamic interactions may play a fundamental role in the price formation process of electricity wholesale markets (Knitell and Roberts, 2005) and multivariate analysis of simultaneous equations is the only technique that avoids the endogeneity problems by treating all variables (electricity price, fuel prices and EUA prices) to be endogenous. Multivariate analysis has been developed using either the VAR models or cointegrated VAR (CVAR) models. As noted (Engle and Granger, 1987), there are strong beliefs that economic data are non-stationary, meaning any particular price measure over time will not be tied to its historical mean. So, modelling that kind of data by a levels VAR model appears to be inadequate, because of spurious regression risk, thus requiring one of the two solutions:

1 modelling a VAR in first differences which may impose the risk of loss relevant information about long-term relationships

2 specify a CVAR, if the variables show a very interesting property, namely the cointegration.

The latter alternative, if it is possible, has the advantage of allowing the simultaneous analysis of the long-run interactions and the short-term adjustments to the equilibrium relationship.

The cointegration concept, introduced by Engle and Granger (1987), means that individual economic variables may be non-stationary and wander through time, but it is expected not to be completely independent of each other. That is, similar economic forces influence each variable and it is expected that the different variables will tied together. In a more formal way, it is possible that two or more variables are non-stationary and wander through time, but a linear combination of them may, over time, converges to a 
stationary process. Such a process, if present, may reflect the long-run equilibrium relationship, and is referred to as the cointegration equation. According to Engle and Granger (1987), cointegrated variables must have an error correction representation in which an error correction term (ECT) must be incorporated into the model. Accordingly, a VECM is formulated to reintroduce the information lost in the differencing process, thereby allowing for long-run equilibrium as well as short-run dynamics.

Since the influential work of Engle and Granger (1987) several procedures have been proposed for testing the null hypothesis that two or more non-stationary time series are not cointegrated, meaning there exist no linear combinations of the series that are stationary. One approach is to use likelihood ratio tests based on estimation a VAR. This approach was first proposed by Johansen (1988) and refined further by Johansen and Juselius (1990) and Johansen (1991, 1992, 1994). Johansen's approach provides a unified framework for estimation and testing in the context of a multivariate VECM.

The cointegration test procedure specifies a VAR of order $\mathrm{k}$, without imposing any restriction a priori, in the form of error correction model (ECM). Assuming the existence of cointegration, the data generating process $P_{t}$ can be appropriately modelled as a VECM with $k-1$ lags (which is derived from a levels VAR with $k$ lags). Consider a VAR of order $k$ with a deterministic part given by $\mu_{t}$. One can write the $p$-variate process as $P_{t}=\mu_{t}+A_{1} P_{t-1}+A_{2} P_{t-2}+\ldots+A_{k} P_{t-k}+\varepsilon_{t}$. Taking the variables in first differences, with $\Delta$ as the difference operator $\left(\Delta P=P_{t}-P_{t-1}\right)$, than $P_{t-\mathrm{i}} \equiv P_{t-1}-\left(\Delta P_{t-1}+\Delta P_{t-2}+\ldots+\Delta P_{t-i+1}\right)$ and one can re-write the process as:

$$
\Delta P_{t}=\Pi P_{t-1}+\sum_{i=1}^{k-1} \Gamma_{i} \Delta P_{t-i}+\mu_{i}+\varepsilon_{i}
$$

where $\Pi=\sum_{i=1}^{k} A_{i}-I ; \quad \Gamma_{i}=-\sum_{j=i+1}^{k} A_{j}$ and $\varepsilon_{t} \sim \operatorname{Niid}(0, \Sigma)$

In equation (1) $P_{t}$ represents a vector of $p$ non-stationary endogenous variables and the matrix $\Pi$ contains information about the long-run relationship among endogenous variables and can be decomposed as $\Pi=\alpha \beta$, whereas $\beta$ represents the cointegration vectors and $\alpha$ the matrix with the estimations on the speed of adjustment to the equilibrium. The matrix $\Pi$ is called an ECT, which compensates for the long-run information lost through differencing (Juselius, 2006). The rank of matrix $\Pi(r)$ determines the long-run relationship. If the rank of the matrix $\Pi$ is zero $(r=0)$, there is no long-run relationship and the model above is equal to a VAR in differences. If the matrix $\Pi$ has the full rank $(r=p)$, then it is invertible, meaning that the processes $\mathrm{P}_{t}$ is stationary $I(0)$ and a normal VAR in levels can be used. The cointegration relationship occurs when the order of the matrix is between 0 and $p(0<r<p)$ and there are $(p x r)$ matrices $\alpha$ and $\beta$ such that the equation $\Pi=\alpha \beta$ holds. In this case, $P_{t}$ is $I(1)$ but the linear combination $X_{t}=\beta P_{t}$ is $I(0)$. If, for example, $r=1$ and the first element of $\beta$ was $\beta=-1$, then one could write the linear combination as $X_{t}=-P_{1, t}+\beta_{2} P_{2, t}+\ldots+\beta_{p} P_{p, t}$, which is equivalent to saying that long-run equilibrium relationship among variables of vector $P_{t}$ is expressed as $P_{1, t}=\beta_{2} P_{2, t}+\ldots+\beta_{p} P_{p, t}-X_{t}$. This long-run relationship may not holds all the time, however the deviation $X_{t}$ are stationary $I(0)$. In this case, equation (1) can be written as: 


$$
\Delta P_{t}=\alpha \beta^{\prime} P_{t-1}+\sum_{i=1}^{k-1} \Gamma_{i} \Delta P_{t-1}+\mu_{t}+\varepsilon_{t}
$$

If $\beta$ were known, then $X_{t}$ would be observable and all the remaining parameters could be estimated by OLS. In practice, the procedure estimates $\beta$ first and then the rest.

An error correction model provides two alternative channels of the interaction among variables:

1 short-run effects of the variables are captured similar to the VAR of differences, whose parameters are estimated in the matrix $\Gamma_{i}$

2 the long-run effects enter the model with the term $\Pi P_{t-1}$ or $\alpha \beta P_{t-1} \cdot \mu_{t}$, is a vector of deterministic terms (constant and trend) and $\varepsilon_{t}$ is a vector of innovations reflecting new information emanating from each of the variables.

The approach first proposed by Johansen (1988) and Johansen and Juselius (1990) was been extended later by Harbo et al. (1998) and Pesaran et al. (2000) to includes exogenous variables in the model, which in our case is particularly useful because it allows an adequate treatment of the generation mix and temperatures variables.

Estimation typically proceeds in two stages: first, a sequence of tests is run to determine $r$, the cointegration rank. Then, for a given rank the parameters of equation (1) are estimated. The rank of $\Pi$ (row rank of $\beta$ ) determines the number of cointegration vectors. Usually two tests on the eigenvalues are used to determine $r$ : trace test and $\lambda_{\max }$ Statistics.

\section{Data}

This study covers the period corresponding to the Phase II of EU ETS, running from January 2, 2008, to August 31, 2011. We use daily data for working days ${ }^{5}$. The electricity series, from OMEL, is the day-ahead price $(€ / \mathrm{MWh})$ for the peak load regime. The peak price is the hourly average of spot prices quoted from 8:00 h to 20:00 $\mathrm{h}$. The natural gas price ( $€ / M W h$ gas) is the spot price from the Zeebrugge $\mathrm{Hub}^{6}$. The coal price $(€ /$ ton.) is the spot index API\#2 (CIF ARA ${ }^{7}$ ). The EUA price series (€/ton.) is the spot price quoted at EEX - European Energy Exchange (Leipzig, Germany) ${ }^{8}$. We transformed the price variables into their natural logarithms to reduce variability, and thus obtaining directly the elasticity values from the parameter estimates.

Regarding air temperature data ${ }^{9}$, we use the daily temperatures (minimum and maximum) at the representative weather stations weighted by the population (NUTS II - Eurostat). To control the model for the marginal technology in the market, we defined five variables according to the technologies present in the Portuguese power generation mix (excluding the renewables): CCGT, thermal coal, thermal fuel, hydroelectric and international trade (imports/exports). Each variable is defined as the ratio between the quantity of electricity traded that is produced by the technology and the total amount of electricity traded in the market. For instance, the variable mix $_{t}^{\text {ccgt }}=0.35$ means that, on day $t, 35 \%$ of all traded electricity was produced by CCGT technology. These variables, as the air temperature variables, are treated in the econometric model as exogenous variables. 
Table 2 Summary statistics

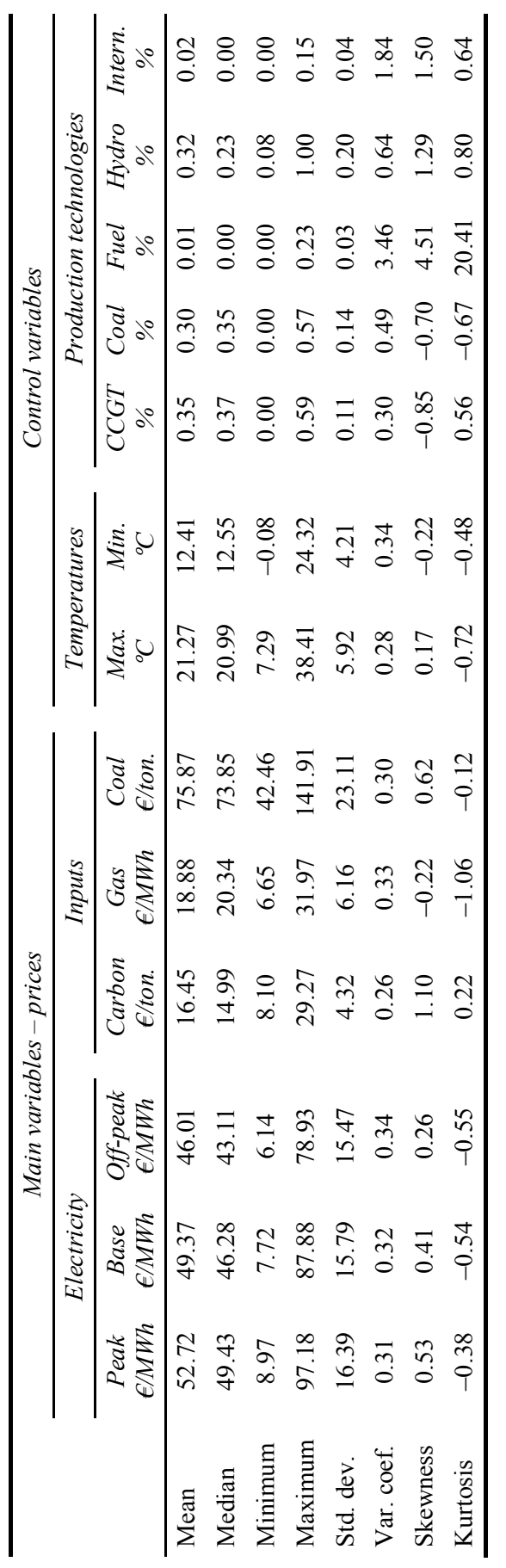


In Figure 1, we should underline the two extreme electricity price peaks at the winters of 2010 and 2011, which matched the peaks in the electricity produced by hydroelectric technology.

Figure 1 Daily commodities prices and mix of electricity generation technologies (see online version for colours)

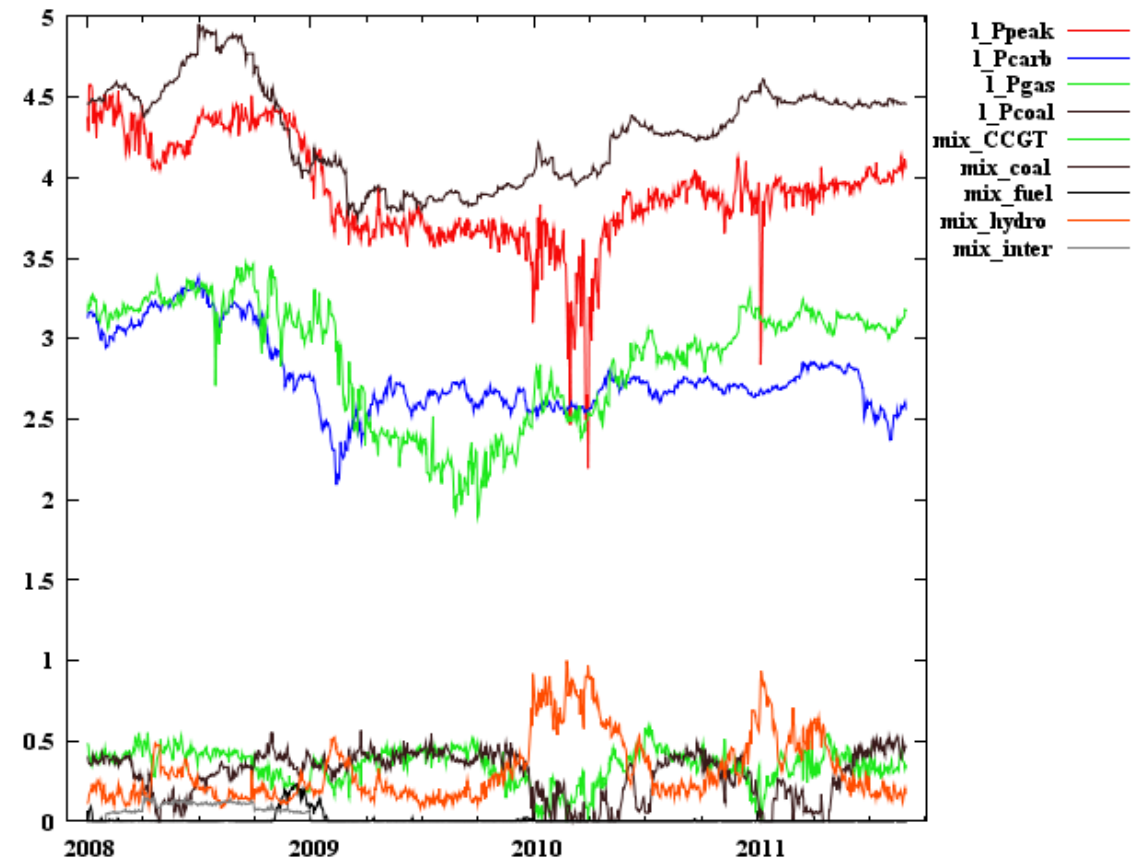

Note: Time series plots of natural logarithms of prices of electricity peak load (OMEL),

EUA (spot, EEX), natural gas (Zeebrugge), coal (API\#2 - CIF ARA) and the variables of generation technologies.

\section{Empirical results}

The estimation method proceeds as follows:

1 unit root (UR) tests are conduct to test for the order of integration in individual price series

2 assuming the tests conclude that the series are $I(1)$, the cointegration rank is determined

3 a VECM is estimate. 
12 C.J.P. Freitas and P.P. da Silva

Table 3 UR tests

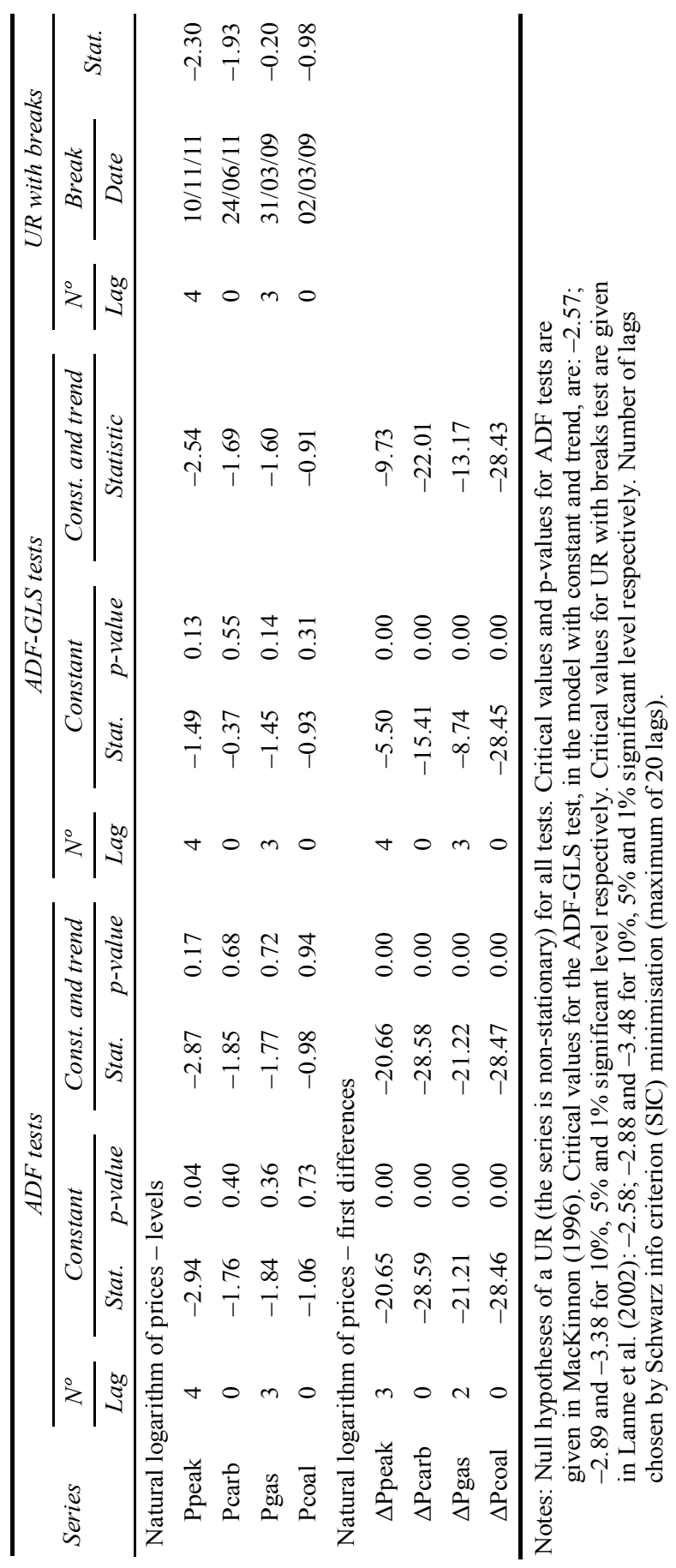




\subsection{Preliminary tests}

We start our estimation procedure by testing the existence of a UR in data. Traditional augmented Dickey-Fuller tests (ADF tests) and the more efficient Dickey-Fuller generalised least squares tests (ADF-GLS tests) are conducted using the natural logarithms of the price series (electricity, EUA, natural gas and coal). As shown in Table 3, all series fail to reject the null of a UR for all specifications tested at a $5 \%$ level except for electricity price (ADF test with only a constant). However, the UR tests with Breaks, which allow accounting for the possibility of level shift (Lanne et al., 2002), confirm the non-stationarity of the electricity prices. With linear trend and a constant include, tests for all series fail to reject the non-stationary null. However, no linear trend is apparent in any of the series.

\subsection{Econometric model}

Given the order of integration of the variables used, a general VECM specification can be formulated as:

$$
\Delta P_{t}=\alpha \beta^{\prime} P_{t-1}+\sum_{i=1}^{k-1} \Gamma_{i} \Delta P_{t-i}+\Phi Z_{t}+\mu_{t}+\varepsilon_{t} ; \quad \varepsilon_{t} \sim \operatorname{Niid}(0, \Sigma)
$$

where $P_{t}$ is a $(4 \times 1)$ vector of prices (endogenous variables) measured at time $t$ : $P_{t}=\left[\mathrm{P}_{t}^{\text {peak }}, \mathrm{P}_{t}^{\text {carb }}, \mathrm{P}_{t}^{\text {gas }}, \mathrm{P}_{t}^{\text {coal }}\right]-\mathrm{P}_{t}^{\text {peak }}$ is the natural logarithm of electricity price, $\mathrm{P}_{t}^{\text {carb }}$ is the natural logarithm of $\mathrm{CO}_{2}$ emission allowances price, $\mathrm{P}_{t}^{\text {gas }}$ is the natural logarithm of natural gas price and $\mathrm{P}_{t}^{\text {coal }}$ is the natural logarithm of coal price. $\alpha$ and $\beta$ are $(4 \times r)^{10}$ matrix, whereas $\beta$ and $\alpha$ represent the cointegrating vectors and the matrix with the estimations on the speed of adjustments to the equilibrium, respectively.

Where $\Gamma_{i}$ is a $(4 \times 4)$ matrix with the estimations of short-run parameters relating price changes lagged i periods.

Where $\Phi$ is a $(4 \times 7)$ matrix of coefficients associated with the $(7 \times 1)$ vector $Z_{t}$ that represents the exogenous variables: $Z_{t}=\left[\mathrm{mix}_{t}^{\text {ccgt }}, \mathrm{mix}_{t}^{\text {coal }}, \mathrm{mix}_{t}^{\text {fuel }}, \mathrm{mix}_{t}^{\text {hydro }}, \mathrm{mix}_{t}^{\text {int }}\right.$, temp ${ }_{t}^{\text {max }}$, temp $\left._{t}^{\text {min }}\right]-$ mix $_{t}^{\text {ccgt }}$ is the $\%$ of electricity traded on day $t$ produced in CCGT, mix $_{t}^{\text {coal }}$ is the $\%$ of electricity traded on day $t$ produced in coal-fired thermal power plant, $\operatorname{mix}_{t}^{\text {fuel }}$ is the $\%$ of electricity traded on day $t$ produced in fuel-fired thermal power plant, $\mathrm{mix}_{t}^{\text {hydro }}$ is the $\%$ of electricity traded on day $t$ produced in Hydroelectric power plant, $\operatorname{mix}_{t}^{\text {int }}$ is the $\%$ of electricity traded on day $t$ originating in the international market, temp ${ }_{t}^{\max }$ is the maximum temperature occurred on day $t$ and temp ${ }_{t}^{\min }$ is the minimum temperature occurred on day $t$.

Where $\mu_{t}$ is a $(4 \times 1)$ vector of constant ${ }^{11}$ and $\varepsilon_{t}$ is a $(4 \times 1)$ vector of innovations. 


\subsection{Cointegration tests}

The first step in modelling procedure is to determine the lag relationship among the price series in a levels VAR [used to generate equation (3)]. Both the Akaike info criterion (AIC) and Hannan and Quinn criterion (HQC) loss metrics suggest the appropriate VAR lag length is two ${ }^{12} K=2$ (Table 4). Further, all the three metrics indicates the inclusion of exogenous variables (both the generation mix variables and weather variables) improves the fit of the VAR to the data. Results in Table 5 suggest not include lags in the exogenous variables.

The tests of cointegration were implemented with the technique based on the reduced rank regression introduced in Johansen (1991). Since the VAR model contains exogenous variables, the Osterwald-Lenum (1992) and Johansen (1995) asymptotic critical values are no longer valid, and we therefore use the asymptotic critical values provided in Mackinnon et al. (1999), which results from improvements made to the work in Pesaran et al. $(2000)^{13}$. The decision of whether the constant is within or outside of the cointegration space was based on the three metrics, and the results recommend restricting the intercept to lie in the cointegration space.

The results for both trace test and $\lambda_{\max }$ statistics, presented in Table 6 , clearly indicate the existence of one cointegrated vector. So, we proceed under the result of a single long-run relationship among the variables.

Table 4 Lag length in endogenous variables

\begin{tabular}{cccc}
\hline Lags & AIC & SIC & $H Q C$ \\
\hline Constant and exogenous variables & & \\
1 & -14.237 & -13.980 & -14.139 \\
2 & -14.286 & -13.943 & -14.155 \\
No constant and exogenous variables & & \\
1 & -14.236 & -14.000 & -14.146 \\
2 & -14.282 & -13.961 & -14.159 \\
Constant and no exogenous variables & & \\
1 & -14.052 & -13.945 & -14.011 \\
2 & -14.136 & -13.943 & -14.062 \\
3 & -14.132 & -13.854 & -14.026 \\
4 & -14.136 & -13.772 & -13.997 \\
No constant and no exogenous variables & & \\
1 & -14.033 & -13.948 & -14.001 \\
2 & -14.123 & -13.951 & -14.057 \\
3 & -14.123 & -13.866 & -14.025 \\
4 & -14.129 & -13.786 & -13.998 \\
5 & -14.130 & -13.702 & -13.967 \\
\hline
\end{tabular}

Note: Model with constant and a maximum of 20 lags. 
Table 5 Lag length in exogenous variables

\begin{tabular}{|c|c|c|c|}
\hline Lags & $A I C$ & $S I C$ & $H Q C$ \\
\hline \multicolumn{4}{|c|}{ Lags in exogenous variables $=0$} \\
\hline 1 & -14.2370 & -13.9797 & -14.1387 \\
\hline 2 & -14.2865 & -13.9435 & -14.1554 \\
\hline \multicolumn{4}{|c|}{ Lags in exogenous variables $=1$} \\
\hline 1 & 14.2318 & -13.8245 & -14.0762 \\
\hline 2 & -14.2862 & -13.7931 & -14.0978 \\
\hline \multicolumn{4}{|c|}{ Lags in exogenous variables $=2$} \\
\hline 1 & -14.2082 & -13.6508 & -13.9952 \\
\hline 2 & -14.2638 & -13.6207 & -14.0181 \\
\hline \multicolumn{4}{|c|}{ Lags in exogenous variables $=3$} \\
\hline 1 & -14.1839 & -13.4765 & -13.9136 \\
\hline 2 & -14.2402 & -13.4470 & -13.9371 \\
\hline
\end{tabular}

Note: Model with constant and a maximum of 20 lags in the endogenous variables.

Table 6 Cointegration tests

\begin{tabular}{|c|c|c|c|c|c|c|c|}
\hline \multicolumn{2}{|c|}{$H_{O}:$} & \multicolumn{3}{|c|}{ Trace test } & \multicolumn{3}{|c|}{$\lambda_{\max }-$ max eigen value test } \\
\hline$r=$ & $p-r=$ & Statistics & $\begin{array}{c}\text { Critical } \\
\text { values }\end{array}$ & p-values & Statistics & $\begin{array}{l}\text { Critical } \\
\text { values }\end{array}$ & p-values \\
\hline 0 & 4 & 244.87 & 118.85 & 0.00 & 171.42 & 50.58 & 0.00 \\
\hline 1 & 3 & 73.46 & 85.26 & 0.24 & 42.75 & 43.87 & 0.06 \\
\hline 2 & 2 & 30.70 & 55.35 & 0.86 & 25.14 & 36.76 & 0.49 \\
\hline 3 & 1 & 5.57 & 28.71 & 1.00 & 5.57 & 28.71 & 1.00 \\
\hline
\end{tabular}

Notes: $5 \%$ significant level for critical values is. $p$-values calculated using the software in Mackinnon et al. (1999). Model with restricted constant (Case II), two lags in endogenous variables and seven exogenous variables.

\subsection{VECM estimation}

With the cointegration rank and optimum number of lags determined, the parameters of model (3) can be estimated. To do this we used the software GRETL ${ }^{14}$ and the maximum likelihood approach proposed by Johansen (1991). The results reported in Table 7 for the cointegrated vector $\beta$, which is normalised on $P_{t-1}^{\text {peak }}$, show that all estimated parameters have the correct sign and they are all significant according to the likelihood ration test as showed in Johansen (1995). Since the coefficients can be interpreted as price elasticities, therefore, a EUA price rise of $1 \%$, would, in equilibrium, be associated with an electricity price rise of $0.51 \%(0.31 \%$ in the natural gas price and $0.29 \%$ in coal price). In addition, it appears from the parameter estimates for the adjustment coefficients $\alpha$, and weak exogeneity tests described in Juselius (2006), for 1\% significance, only the electricity price series reject the null, meaning that the long-run relationships in the data are important only for the electricity price. These results are expected since EUA, natural gas and coal are commodities traded global and thus may be driven more by forces outsider 
the Iberian energy market. As one can see, the evidence of weak exogeneity is not so strong in the case of coal prices.

The short-run parameters in the VAR are all significant except for natural gas price. In the case of the exogenous variables, we could confirm that the electricity generation mix is important for the short run dynamics of electricity price. There is also strong evidence that the weather variables are important for electricity price changes in the short-run. As expected, the effected of temperature on price changes is non-linear - there is a positive relationship between price changes and maximum temperature (which reflect demand of electricity essential for cooling) and a negative relationship between price changes and minimum temperature (which reflect demand of electricity essential for heating). Moreover, not only is the sign reversed, but also the magnitude of the coefficient is different: the coefficient associated with the minimum temperature $\left(\Phi_{\text {tempmin }}=-0.007\right)$ is almost the double of the coefficient associated with the maximum temperature $\left(\Phi_{\text {tempmax }}=0.004\right)$. The same result, but in the opposite direction, was reported by Fezzi and Bunn (2006) for the Nordpool - in this case the demand for electricity (and price) is more sensible to the high temperatures, which can be explained by the different habits of energy consumption according to the very different latitudes of the two markets.

Table $7 \quad$ VECM parameter estimates

\begin{tabular}{|c|c|c|c|c|}
\hline \multicolumn{5}{|c|}{ Cointegration relationship } \\
\hline$P_{t}^{\text {peak }}$ & $P_{t}^{\text {carb }}$ & $P_{t}^{\text {gas }}$ & $P_{t}^{\text {coal }}$ & Const. \\
\hline \multirow[t]{2}{*}{$1.000 * * *$} & $-0.514 * * *$ & $-0.311^{* * *}$ & $-0.290^{* * *}$ & $2.113^{* * *}$ \\
\hline & $(0.09)$ & $(0.06)$ & $(0.09)$ & $(0.64)$ \\
\hline \multicolumn{5}{|c|}{ Short run dynamics } \\
\hline & $\Delta P_{t}^{\text {peak }}$ & $\Delta P_{t}^{\text {carb }}$ & $\Delta P_{t}^{g a s}$ & $\Delta P_{t}^{\text {coal }}$ \\
\hline$E C_{t-1}$ & $-0.317 * * *$ & $0.012 *$ & - & $-0.015^{* *}$ \\
\hline$\Delta P_{t-1}^{\text {peak }}$ & $-0.149 * * *$ & - & - & - \\
\hline$\Delta P_{t-1}^{\text {carb }}$ & $-0.244 * *$ & - & $0.197^{* *}$ & $0.142 * * *$ \\
\hline$\Delta P_{t-1}$ gas & $-0.091 *$ & - & $-0.124 * * *$ & $0.025^{* *}$ \\
\hline$\Delta P_{t-1}^{\text {coal }}$ & - & $-0.110^{* * *}$ & - & - \\
\hline $\operatorname{mix}_{t}^{\text {ccgt }}$ & $0.818^{* * *}$ & - & - & $0.043^{* * *}$ \\
\hline $\operatorname{mix}_{t}^{\text {coal }}$ & $0.928^{* * *}$ & $-0.039^{*}$ & - & $0.046^{* *}$ \\
\hline $\operatorname{mix}_{t}^{\text {fuel }}$ & $1.240^{* * *}$ & $-0.109^{* * *}$ & - & - \\
\hline $\operatorname{mix}_{t}^{\text {hydro }}$ & $0.652^{* * *}$ & - & - & $0.034 * *$ \\
\hline $\operatorname{mix}_{t}^{\text {int }}$ & $0.417 * * *$ & - & - & - \\
\hline temp ${ }_{t}^{\max }$ & $0.004 * * *$ & - & - & - \\
\hline $\operatorname{temp}_{t}^{\min }$ & $-0.007 * * *$ & - & - & - \\
\hline
\end{tabular}

Notes: $\mathrm{EC}_{t-1}$ refers to the adjustment coefficients $(\alpha)$. We only present the significant coefficients. Standard errors in parentheses. ${ }^{* * *}$ Significant at $1 \%$ level.

**Significant at $5 \%$ level. *Significant at $10 \%$ level.

Residuals analysis is conducted for model diagnostic testing (Table 8). Although there is no serial correlation, there is evidence of autoregressive conditional heterocedasticity $(\mathrm{ARCH})$ and non-normality in the residuals. However, this is not likely to be a major 
problem in our cointegration analysis since (Gonzalo, 1994) showed that the properties of asymptotically optimal inferences present on maximum likelihood estimators hold in finite samples even without the normality assumption. Observing the residuals correlation matrix (Table 9) we can see that the correlations among all equations are very low.

Table 8 Diagnostic tests on residuals

\begin{tabular}{|c|c|c|c|c|}
\hline \multicolumn{5}{|c|}{ Diagnostic tests on residuals } \\
\hline \multicolumn{5}{|c|}{ Serial correlation $\left(\mathrm{H}_{0}\right.$ : serially uncorrelated $)$} \\
\hline Ljung & $\mathrm{x} \mathrm{Q}^{\prime}(5)$ & & 5.5271 & $(0.355)$ \\
\hline \multicolumn{5}{|c|}{ Heterocedasticity $\left(\mathrm{H}_{0}\right.$ : homokedastic) } \\
\hline $\mathrm{ARC}$ & & & 207.012 & $(0.000)$ \\
\hline \multicolumn{5}{|c|}{ Normality $\left(\mathrm{H}_{0}:\right.$ normal distributed) } \\
\hline Door & Hansen (8) & & $4,477.65$ & $(0.000)$ \\
\hline \multicolumn{5}{|c|}{ Note: $p$-values in parentheses. } \\
\hline Table 9 & Residuals & & & \\
\hline$\Delta P^{\text {peak }}$ & 1 & 0.044 & 0.021 & -0.044 \\
\hline$\Delta P^{\mathrm{carb}}$ & - & 1 & -0.008 & -0.03 \\
\hline$\Delta P^{\mathrm{gas}}$ & - & - & 1 & 0.044 \\
\hline$\Delta P^{\text {coal }}$ & - & - & - & 1 \\
\hline
\end{tabular}

\section{Conclusions}

This study uses a VECM approach to conclude about the relationship between electricity prices and $\mathrm{CO}_{2}$ emissions allowances prices for the MIBEL (Portuguese division) in the context of the Phase II of EU ETS (2008-2011). An econometric model was developed that encompasses long-run and equilibrium and short-run effects in the dynamic interactions between electricity, carbon, gas and coal prices. It was possible to control the effect of input prices in electricity price by using two sets of exogenous variables: one, reflecting the demand for electricity conditions (temperatures) and the other, reflecting the production mix (weight of each technology present in the production mix of the total energy traded in the market). Using daily data, it is shown that carbon price plays an important role in formulating the equilibrium price of electricity and, as the other fuels, stands essentially exogenous in the long run. The long-run elasticity of electricity price to carbon price shocks, herein the $\mathrm{CO}_{2}$ Cost Pass-Through, is 51\%, meaning that, in the long-run, a $1 \%$ shock in carbon prices impacts, on average, into a $0.51 \%$ shock in electricity prices. Our results compare with $93 \%$ in Honkatukia et al. (2006) for the NordPool market, 32\% in Fezzi and Bunn (2009) for the UK market, (11\%-13\%) in Fell (2010) for the NordPool market and 36\% in Thoenes (2011) for the German market. In addition, the results found for the long-run PTR of $\mathrm{CO}_{2}$ prices into electricity price are just below the simulations (COMPETES model) for the Portuguese market $(56 \%-64 \%)$ in Sijm et al. (2008) and (58\%-100\%) in Lise et al. (2010).

Concluding, the results we have estimated for the Portuguese wholesale electricity market, not only in accordance with studies for other different European electricity 
markets, confirm evidence of a significant link between carbon prices and electricity prices demonstrating that power producers have been passed on the opportunity costs of freely allocated emissions allowances to electricity prices, enabling power companies to get windfall profits. According to these conclusions the competitiveness of the power producers may not be affected if companies have to pay for emissions allowances, which therefore would result in a distributive impact on consumer's surplus and firm's profits. Therefore, these results support the changing in the allocation rule of emissions allowances to the electricity sector, from grandfathering to auctioning, proposed by the European Commission for the next phase of the EU ETS starting in 2013.

\section{Acknowledgements}

For the useful suggestions and comments on Portuguese electric system from Eduardo Teixeira and Ricardo Pacheco.

For freely provided data on weather: see Tank et al. (2002).

The second author would like to acknowledge that this work has been partially supported by FCT, under project grant PEst-C/EEI/UI0308/2011, and the Energy for Sustainability Initiative of the University of Coimbra and supported by the R\&D Project EMSURE (Energy and Mobility for Sustainable Regions) - CENTRO 070224 FEDER 002004.

\section{References}

Alberola, E., Chevallier, J. and Chèze, B. (2008) 'Price drivers and structural breaks in European carbon prices: 2005-2007', Energy Policy, Vol. 36, No. 2, pp.787-797.

Alberola, E., Chevallier, J. and Chèze, B. (2009) 'Emissions compliances and carbon prices under the EU ETS: a country specific analysis of industrial sectors', Journal of Policy Modelling, Vol. 31, No. 3, pp.446-462.

Bunn, D. (2004) 'Structural and behavioural foundations of competitive electricity prices', in Modelling Prices in Competitive Electricity Markets, John Wiley and Sons, Ltd., pp.1-17.

Bunn, D. and Fezzi, C. (2007) Interaction of European Carbon Trading and Energy Prices, Fondazione Eni Enrico Mattei, Milano.

Burtraw, D. and Palmer, K. (2008) 'Compensation rules for climate policy in the electricity sector', Journal of Policy Analysis and Management, Vol. 27, No. 4, pp.819-847.

Chemarin, S., Heinen, A. and Strobl, E. (2008) Electricity, Carbon and Weather in France: Where do We Stand?, Ecole Polytechnique, Centre National de la Recherche Scientifique.

Chen, Y., Sijm, J., Hobbs, B. and Wietze, L. (2008) 'Implications of $\mathrm{CO}_{2}$ emissions trading for short-run electricity market outcomes in Northwest Europe', Journal of Regulatory Economics, Vol. 34, No. 3, pp.251-281.

Chevallier, J. (2010) 'The impact of Australian ETS news on wholesale spot electricity prices: an exploratory analysis', Energy Policy, Vol. 38, No. 8, pp.3910-3921.

Daskalakis, G. and Markellos, R. (2009) 'Are electricity risk premia affected by emission allowance prices? Evidence from the EEX, Nord Pool and Powernext', Energy Policy, Vol. 37, No. 7, pp.2594-2604.

Engle, R. and Granger, W. (1987) 'Co-integration and error correction: representation, estimation, and testing', Econometrica, Vol. 55, No. 2, pp.251-276. 
Engle, R., Granger, C., Rice, J. and Weiss, A. (1986) 'Semiparametric estimates of the relation between weather and electricity sales', Journal of the American Statistical Association, Vol. 81, No. 394, pp.310-320.

European Commission (2003) 'Establishing a scheme for greenhouse gas emission allowance trading within the community and amending Council Directive 96/61/EC', Directive 2003/87/EC of the European Parliament and of the Council of 13 October 2003.

Fell, H. (2010) 'EU-ETS and Nordic electricity: a CVAR analysis', The Energy Journal, Vol. 31, No. 2, pp.1-25.

Ferkingstad, E., Løland, A. and Wilhelmsen, M. (2011) 'Causal modeling and inference for electricity markets', Energy Economics, Vol. 33, No. 3, pp.404-412.

Fezzi, C. (2006) Econometric Analysis of the Interaction between the European Emissions Trading Scheme and Energy Prices (draft), London Business School - Department of Decision Science, London.

Fezzi, C. and Bunn, D. (2006) Structural Analysis of High-Frequency Electricity Demand and Supply Interactions, London.

Fezzi, C. and Bunn, D. (2009) 'Structural interactions of European carbon trading and energy prices', The Journal of Energy Markets, Vol. 2, No. 4, pp.53-69.

Frondel, M., Schmidt, C. and Vance, C. (2008) Emissions Trading: Impact on Electricity Prices and Energy Intensive Industries, Ruhr Economic Papers, Germany.

Gonzalo, J. (1994) 'Five alternative methods of estimating long-run equilibrium relationships', Journal of Econometrics, Vol. 60, No. 1, pp.203-233.

Gullì, F. (2008) 'Modelling the short-run impact of 'carbon trading' on the electricity sector with endogenous market power', in Markets for Carbon and Power Pricing in Europe: Theoretical Issues and Empirical Analyses, Edward Edgar, Cheltenham.

Harbo, I., Johansen, S., Nielsen, B. and Rahbek, A. (1998) 'Asymptotic inference on cointegrating rank in partial systems', Journal of Business Economics and Statistics, Vol. 16, No. 4, pp.388-399.

Hauch, J. (2003) 'Electricity trade and $\mathrm{CO}_{2}$ emission reductions in the Nordic countries', Energy Economics, Vol. 25, No. 5, pp.509-526.

Hintermann, B. (2010) 'Allowance price drivers in the first phase of the EU ETS', Journal of Environmental Economics and Management, Vol. 59, No. 1, pp.43-56.

Honkatukia, J., Malkonen, V. and Perrels, A. (2006) Impacts of the European Emissions Trade System on Finnish Wholesale Electricity Prices, Government Institute for Economic Researchs, Helsinki.

Johansen, S. (1988) 'Statistical analysis of cointegrating vectors', Journal of Economic Dynamics and Control, Vol. 12, Nos. 2-3, pp.231-254.

Johansen, S. (1991) 'Estimation and hypothesis testing of cointegration vectors in Gaussian vector autoregressive models', Econometrica, Vol. 59, No. 6, pp.1.551-1.580.

Johansen, S. (1992) 'Determination of cointegration rank in the presence of a linear trend', Oxford Bulletin of Economics and Statistics, Vol. 54, No. 3, pp.383-397.

Johansen, S. (1994) 'The role of the constant and linear terms in cointegration analysis of nonstationary variables', Econometric Reviews, Vol. 13, No. 2, pp.205-229.

Johansen, S. (1995) Likelihood-based Inference in Cointegrated Vector Autoregressive Models, Oxford University Press, New York.

Johansen, S. and Juselius, K. (1990) 'Maximum likelihood estimation and inference on cointegration - with applications to the demand for money', Oxford Bulletin of Economics and Statistics, Vol. 52, No. 2, pp.169-210.

Juselius, K. (2006) The Cointegrated VAR Model, Oxford University Press, Oxford.

Kara, M. et al. (2008) 'The impacts of $\mathrm{EU} \mathrm{CO}_{2}$ emissions trading on electricity markets and electricity consumers in Finland', Energy Economics, Vol. 30, No. 2, pp.193-211. 
Keppler, J. and Mansanet-Bataller, M. (2010) 'Causalities between $\mathrm{CO}_{2}$, electricity, and other energy variables during Phase I and Phase II of the EU ETS', Energy Policy, Vol. 38, No. 7, pp.3329-3341.

Knitell, R. and Roberts, R. (2005) 'An empirical examination of restrutured electricity prices', Energy Economics, Vol. 27, No. 5, pp.791-817.

Lanne, M., Lutkepohl, H. and Saikkonen, P. (2002) 'comparison of unit root tests for time series with level shifts', Journal of Time Series Analysis, Vol. 23, No. 6, pp.667-685.

Levy, C. (2005) Impact of Emission Trading on Power Prices. A Case Study from the European Emission Trading Scheme, DEA d'Economie Industrielle and Université Paris Dauphine, Paris.

Linares, P. et al. (2006) 'Impacts of the European emissions trading scheme directive and permit assignment methods on the Spanish electricity sector', The Energy Journal, Vol. 27, No. 1, pp.79-98.

Lise, W., Sijm, J. and Hobbs, F. (2010) 'The impact of the EU ETS on prices, profits and emissions in the power sector: simulation results with the COMPETES EU20 model', Environmental and Resource Economics, Vol. 47, No. 1, pp.23-44.

MacKinnon, J. (1996) 'Numerical distribution functions for unit root and cointegration tests', Journal of Applied Econometrics, Vol. 11, No. 6, pp.601-618.

Mackinnon, J., Haug, A. and Michelis, L. (1999) 'Numerical distribution functions of likelihood ratio tests for cointegration', Journal of Applied Econometrics, Vol. 14, No. 5, pp.563-577.

Mansanet-Bataller, M., Pardo, A. and Valor, E. (2007) ' $\mathrm{CO}_{2}$ prices, energy and weather', The Energy Journal, Vol. 28, No. 3, pp.73-92.

Mjelde, J. and Bessler, D. (2009) 'Market integration among electricity markets and their major fuel source markets', Energy Economics, Vol. 3, No. 3, pp.482-491.

Mohammadi, H. (2009) 'Electricity prices and fuel costs: long-run relations and short-run dynamics', Energy Economics, Vol. 3, No. 3, pp.503-509.

Moutinho, V., Vieira, J. and Moreira, A. (2011) 'The crucial relationship among energy commodity prices: evidence from the Spanish electricity market', Energy Policy, Vol. 39, No. 10, pp.5898-5908.

Neuhoff, K., Martinez, K. and Sato, M. (2006) 'Allocation, incentives and distortions: the impact of EU ETS emissions allowance allocations to the electricity sector', Climate Policy, Vol. 6, No. 1, pp.73-91.

Osterwald-Lenum, M. (1992) 'A note with quantiles of the asymptotic distribution of the maximum likelihood cointegration rank test statistics', Oxford Bulletin of Economics and Statistics, Vol. 54, No. 3, pp.461-471.

Pacheco, R. (2010) Econometric Study of the Spanish Electricity Spot Market and Primary Energy Markets using VAR/VECM methodology (cointegration and nonstationary time series), ISCTE Business School, Department of Quantitative Methods, Lisbon.

Pesaran, M., Shin, Y. and Smith, R. (2000) 'Structural analysis of vector error correction models with exogenous I(1) variables', Journal of Econometrics, Vol. 97, No. 2, pp.293-343.

Reinaud, J. (2007) $\mathrm{CO}_{2}$ Allowance and Electricity Price Interaction - Impact on industry's electricity purchasing strategies in Europe, IEA - International Energy Agency, Paris.

Rickels, W., Görlich, D. and Oberst, G. (2010) Explaining European Emission Allowance Price Dynamics: Evidence from Phase II, Kiel Institute for the World Economy, Kiel.

Rosenblad, A. (2008) 'gretl 1.7.3', Journal of Statistical Software, Vol. 25, No. 1, pp.1-14.

Sijm, J. et al. (2005) $\mathrm{CO}_{2}$ Price Dynamics: The Implications of EU Emissions Trading for the Price of Electricity, ECN - Energy Research Centre of the Netherlands, Amsterdam.

Sijm, J., Hers, S., Lise, W. and Wetzelaer, B. (2008) 'The impact of the EU ETS on electricity prices - final report to DG environment of the European Commission', ECN - Energy Research Centre of the Netherlands, Amsterdam. 
Sijm, J., Neuhoff, K. and Chen, Y. (2006) ' $\mathrm{CO}_{2}$ cost pass through and windfall profits in the power sector', Climate Policy, Vol. 6, No. 1, pp.49-72.

Tank, A.M.G.K. et al. (2002) 'Daily dataset of 20th-century surface air temperature and precipitation series for the European climate assessment', Int. J. of Climatol., Vol. 22, No. 12, pp.1441-1453.

Thoenes, S. (2011) Understanding the Determinants of Electricity Prices and the Impact of the German Nuclear Moratorium in 2011, Institute of Energy Economics at the University of Cologne (EWI), Cologne.

Wals, A. and Rijkers, F. (2003) How Will a $\mathrm{CO}_{2}$ Price Affect the Playing Field in the Northwest European Power Sector?, ECN - Energy Research Centre of the Netherlands.

Zachmann, G. and von Hirschhausen, C. (2007) First Evidence Of Asymmetric Cost Pass-Through of EU Emissions Allowances: Examining Wholesale Electricity Prices in Germany, Massachusetts Institute of Technology and CEEPR - Center for Energy and Environmental Policy Research.

\section{Notes}

1 Free allocation of $\mathrm{CO}_{2}$ allowances on the basis of historical emissions.

2 COMPETES stands for comprehensive market power in electric transmission and energy simulator.

3 In an alternative specification the author considers the reservoir water level as endogenous, considering that hydroelectricity could be used strategically to capture higher electricity prices.

4 In Portugal, unlike the Spanish market, renewable energy is not traded in the wholesale market (OMEL). Producers contracted their energy bilaterally by the last resource supplier.

5 Weekend and national holidays are excluded from this study because demand patterns are substantially different from working days. The difference in demand level for electricity among the three load regimes is substantially lower at the weekend and holidays.

6 European virtual trading point (Belgium).

7 Delivered to the Amsterdam/Rotterdam/Antwerp region.

8 We test prices from other markets, namely ECX - European Climate Exchange (London, UK) and BlueNext (Paris, France) and we did not find significant differences.

9 Source: European Climate Assessment and Dataset - ECA\&D.

10 Where $r$ is the number of cointegrating vectors.

11 Actually $\Pi=\alpha \beta$ may be of order $(4 \times 5)$ or $(4 \times 4)$ depending on whether the constant is inside or outside (restricted or unrestricted) of the cointegration space.

12 As the VAR is specified in first differences, the number of lags lag in the VECM should be one $(k-1)$.

13 The first version was published in 1997, and it was contemporary of Harbo et al. (1998) where the inclusion of exogenous variables in the VECM was also treated. The advantage of Mackinnon et al. (1999) simulations is to allow treatment of up to eight exogenous variables, and recall that in our model we work with seven exogenous variables.

14 'Gretl 1.8.6 for Windows'. One can find a good revision of the software properties in Rosenblad (2008). 